\title{
Editorial \\ Special Issue on Optical In-Process Measurement Systems
}

\author{
Andreas Fischer (iD
}

check for

updates

Citation: Fischer, A. Special Issue on Optical In-Process Measurement Systems. Appl. Sci. 2022, 12, 2664. https://doi.org/10.3390/app12052664

Received: 2 March 2022

Accepted: 3 March 2022

Published: 4 March 2022

Publisher's Note: MDPI stays neutral with regard to jurisdictional claims in published maps and institutional affiliations.

Copyright: (C) 2022 by the author. Licensee MDPI, Basel, Switzerland. This article is an open access article distributed under the terms and conditions of the Creative Commons Attribution (CC BY) license (https:// creativecommons.org/licenses/by/ $4.0 /)$.
Bremen Institute for Metrology, Automation and Quality Science, University of Bremen, Linzer Str. 13, 28357 Bremen, Germany; andreas.fischer@bimaq.de

\section{Introduction}

Optical principles enable precise measurements, down to the quantum mechanical limits, and provide the fastest possible measurement speed: the speed of light. Driven by the ongoing advances in powerful light sources, accurate light modulation possibilities, and efficient light detectors, the capabilities of optical measurement systems are increasing. However, a current challenge is to make use of the benefits of optical principles for inprocess measurements on real-world objects. Examples are flow processes on wind turbines, on airplanes, and in combustors; the thermal and mechanical processes on a workpiece during manufacturing; and the exploration of natural processes on Earth and in space. Studying non-idealized, non-scaled objects during their actual operation is an important task for the field of measurement science, since it allows us to gain new insights from the actual process behavior to be engineered. Furthermore, in-process measurements are required to create in-process controls.

In-process measurement conditions are often challenging and can result in limited optical access, an uncooperative measurement environment, a large measurement distance, a large measurement object, or a low signal-to-noise ratio. In order to break new ground for the transition "from the lab to the app" (from the laboratory to the application), optical in-process measurements have to be realized at the limits of measurability and beyond.

\section{Progress of Optical In-Process Measurement Systems}

This Special Issue covers a wide range of different optical measurement principles and in-process applications.

Regarding production engineering, an overview of recent advances in the optical measurement of the geometry of manufactured components is presented in [1]. In addition, for in situ measurements of the pitch of a diffraction grating, the diffraction pattern of a mode-locked femtosecond laser is studied in [2], while a real-time automated system to perform dual-aperture common-path interferometer phase-shifting is proposed in [3]. Furthermore, an improved Mirau-type coherence scanning interferometer with vibration compensation is described in [4], which widens the range of industrial applicability.

With a focus on $100 \%$ inspection during laser material processing, an inline measurement approach based on low coherence interferometry is presented in [5]. Considering hairpin welding, a camera-based spatter detection method to assess the quality of the inprocess weld is further investigated in [6]. Finally, the in-process measurement capability of speckle photography to quantify not only the 2D but the complete 3D deformation of a loaded workpiece is proved and characterized in [7].

Regarding the engineering of fluid flows, spectroscopy is applied to study the diffusional behavior of new insulating gas mixtures as alternatives to the use of SF6 in medium voltage switchgear in [8]. In addition, for the future development of an active explosion suppression system in coal mines, the optimal wavelength range for the optical sensing of the ignition of methane-air mixtures and coal dust is identified in [9].

Last but not least, two works concerning the in-process flow analysis for and on wind turbines are presented. To reliably assess the wind velocity and thus the suitability of a 
site for building a wind turbine, a novel transportable wind Lidar system with superior resolution is tested and successfully validated in [10]. Regarding the contactless investigation of premature flow transitions (from laminar to turbulent) on running wind turbines, a thermographic flow visualization with an automated, model-based detection is described in [11].

\section{Outlook}

This Special Issue highlights some of the recent achievements in advancing optical measurement systems for in-process applications in the fields of production engineering, process engineering and renewable energy systems. Since measurements are a key element for improving technical processes in terms of sustainability, efficiency and environment friendliness, optical in-process measurements are of increasing importance and will further shape our future world and society.

Funding: This research received no external funding.

Informed Consent Statement: Not applicable.

Acknowledgments: This issue would not be possible without the contributions of the various talented authors, hardworking and professional reviewers, and dedicated editorial team of Applied Sciences. To all of them, many thanks for your contribution and support.

Conflicts of Interest: The author declares no conflict of interest.

\section{References}

1. Bergmann, R.B.; Kalms, M.; Falldorf, C. Optical In-Process Measurement: Concepts for Precise, Fast and Robust Optical Metrology for Complex Measurement Situations. Appl. Sci. 2021, 11, 10533. [CrossRef]

2. Shin, D.W.; Quan, L.; Shimizu, Y.; Matsukuma, H.; Cai, Y.; Manske, E.; Gao, W. In-Situ Evaluation of the Pitch of a Reflective-Type Scale Grating by Using a Mode-Locked Femtosecond Laser. Appl. Sci. 2021, 11, 8028. [CrossRef]

3. Barcelata-Pinzón, A.; Âlvarez-Tamayo, R.I.; Prieto-Cortés, P. A Real-Time Automated System for Dual-Aperture Common-Path Interferometer Phase-Shifting. Appl. Sci. 2021, 11, 7438. [CrossRef]

4. Serbes, H.; Gollor, P.; Hagemeier, S.; Lehmann, P. Mirau-Based CSI with Oscillating Reference Mirror for Vibration Compensation in In-Process Applications. Appl. Sci. 2021, 11, 9642. [CrossRef]

5. Zechel, F.; Jasovski, J.; Schmitt, R.H. Dynamic, Adaptive Inline Process Monitoring for Laser Material Processing by Means of Low Coherence Interferometry. Appl. Sci. 2021, 11, 7556. [CrossRef]

6. Hartung, J.; Jahn, A.; Bocksrocker, O.; Heizmann, M. Camera-Based In-Process Quality Measurement of Hairpin Welding. Appl. Sci. 2021, 11, 10375. [CrossRef]

7. Tausendfreund, A.; Stöbener, D.; Fischer, A. In-Process Measurement of Three-Dimensional Deformations Based on Speckle Photography. Appl. Sci. 2021, 11, 4981. [CrossRef]

8. Espinazo, A.; Lombraña, J.I.; Asua, E.; Pereda-Ayo, B.; Alonso, M.L.; Alonso, R.M.; Cayero, L.; Izcara, J.; Izagirre, J. Diffusional Behavior of New Insulating Gas Mixtures as Alternatives to the SF6-Use in Medium Voltage Switchgear. Appl. Sci. 2022, $12,1436$. [CrossRef]

9. Khokhlov, S.; Abiev, Z.; Makkoev, V. The Choice of Optical Flame Detectors for Automatic Explosion Containment Systems Based on the Results of Explosion Radiation Analysis of Methane- and Dust-Air Mixtures. Appl. Sci. 2022, 12, 1515. [CrossRef]

10. Wilhelm, P.; Eggert, M.; Hornig, J.; Oertel, S. High Spatial and Temporal Resolution Bistatic Wind Lidar. Appl. Sci. 2021, 11, 7602. [CrossRef]

11. Parrey, A.-M.; Gleichauf, D.; Sorg, M.; Fischer, A. Automated Detection of Premature Flow Transitions on Wind Turbine Blades Using Model-Based Algorithms. Appl. Sci. 2021, 11, 8700. [CrossRef] 